Article

\title{
Zinc Supplementation Alters Plasma Aluminum and Selenium Status of Patients Undergoing Dialysis: A Pilot Study
}

\author{
Chih-Hung Guo ${ }^{1}$, Pei-Chung Chen ${ }^{1}$, Guoo-Shyng W. Hsu ${ }^{2}$ and Chia-Liang Wang ${ }^{3, *}$ \\ 1 Micro-Nutrition \& Biomedical Nutrition Labs, Institute of Biomedical Nutrition, \\ Hung Kuang University, Taichung 433, Taiwan; E-Mails: eillyguo@sunrise.hk.edu.tw (C.-H.G.); \\ chenpc@sunrise.hk.edu.tw (P.-C.C.) \\ 2 Department of Nutritional Science, Fu Jen University, Taipei 242, Taiwan; \\ E-Mail: 002613@mail.fju.edu.tw \\ 3 Department of Nephrology, Kuang-Tien General Hospital, Taichung 433, Taiwan \\ * Author to whom correspondence should be addressed; E-Mail: hollyspirit31@yahoo.com.tw; \\ Tel.: +886-4-2662-5111 (ext. 2829); Fax: +886-4-2665-5050.
}

Received: 4 February 2013; in revised form: 27 March 2013 / Accepted: 10 April 2013 / Published: 22 April 2013

\begin{abstract}
End stage renal disease patients undergoing long-term dialysis are at risk for abnormal concentrations of certain essential and non-essential trace metals and high oxidative stress. We evaluated the effects of zinc ( $\mathrm{Zn}$ ) supplementation on plasma aluminum (Al) and selenium (Se) concentrations and oxidative stress in chronic dialysis patients. Zn-deficient patients receiving continuous ambulatory peritoneal dialysis or hemodialysis were divided into two groups according to plasma Al concentrations (HA group, $\mathrm{Al}>50 \mu \mathrm{g} / \mathrm{L}$; and MA group, $\mathrm{Al}>30$ to $\leq 50 \mu \mathrm{g} / \mathrm{L}$ ). All patients received daily oral $\mathrm{Zn}$ supplements for two months. Age- and gender-matched healthy individuals did not receive $\mathrm{Zn}$ supplement. Clinical variables were assessed before, at one month, and after the supplementation period. Compared with healthy subjects, patients had significantly lower baseline plasma Se concentrations and higher oxidative stress status. After two-month $\mathrm{Zn}$ treatment, these patients had higher plasma $\mathrm{Zn}$ and Se concentrations, reduced plasma $\mathrm{Al}$ concentrations and oxidative stress. Furthermore, increased plasma $\mathrm{Zn}$ concentrations were related to the concentrations of $\mathrm{Al}$, Se, oxidative product malondialdehyde (MDA), and antioxidant enzyme superoxide dismutase activities. In conclusion, $\mathrm{Zn}$ supplementation ameliorates abnormally high plasma Al concentrations and oxidative stress and improves Se status in long-term dialysis patients.
\end{abstract}


Keywords: zinc; aluminum; selenium; oxidative stress; long-term dialysis

\section{Introduction}

Patients with end stage renal diseases (ESRD) that require long-term dialysis are a public health concern worldwide. Despite dialysis treatment, these patients still have high morbidity and mortality rates [1]. The major contributing risk factors include wasting, an oxidant-antioxidant imbalance, progressive inflammation, impaired immune responsiveness, and infection [2]. Recent studies have shown that deficiencies in the essential trace elements zinc $(\mathrm{Zn})$ and selenium (Se) are common findings, which predispose patients to the complications noted above [3-6]. However, the mechanisms underlying these disturbances in $\mathrm{Zn}$ and Se homeostasis in long-term dialysis patients remain to be determined.

$\mathrm{Zn}$ is an anti-oxidant, has anti-inflammatory properties, and regulates innate and adaptive immune responses, which makes it crucial for resistance to infection [2]. Zn deficient status is associated with immune system disturbances, poor nutritional status, atherosclerosis, high rates of hospitalization due to infections [7-10], and significant reductions in blood Se concentrations in chronic dialysis patients [11,12]. Conversely, improved $\mathrm{Zn}$ status is associated with alleviating oxidative stress, inflammation, dyslipidemia, and malnutrition in dialysis patients [7,13-15].

Se has antioxidant properties and protects biological systems from oxidative damage. Se also attenuates inflammatory responses and is required for immune system function [2]. Se deficiency contributes to immune system dysfunction, increases the death from infections, and is a higher cardiovascular disease risk for dialysis patients [16,17]. Se supplementation can decrease oxidative stress and inflammatory status, thus improving the nutritional status of dialysis patients [18]. Thus, $\mathrm{Zn}$ and Se appear to have positive synergistic effects [19] and maintaining these trace metals' homeostasis is critical for dialysis patients.

Patients undergoing long-term dialysis are also at risk for excess concentrations of non-essential trace metals [11,12]. In particular, aluminum (Al) is non-essential for life processes and may act as a toxicant; higher Al blood concentrations have been found in dialysis patients compared to healthy subjects [20,21]. Higher Al concentrations, and lower $\mathrm{Zn}$ and Se status, and increased oxidative stress and inflammation have been observed [21]. Oxidative phenomena can be triggered by Al, which decreases both $\mathrm{Zn}$ and Se status and promotes inflammatory processes in animals [22,23]. In rat models, administering $\mathrm{Se}$ or $\mathrm{Zn}$ have protected tissues from Al-induced inflammation and oxidative damage [24,25]. Thus, elevated Al concentrations may be related to interactions with $\mathrm{Zn}$ and $\mathrm{Se}$ and result in a further increase in oxidative stress and inflammation in patients.

Few studies have examined whether reducing oxidative stress will affect concentrations of $\mathrm{Al}$ in the circulation. Improving blood $\mathrm{Zn}$ status reduces oxidative stress and attenuates the progression of kidney damage, which possibly contributes to ameliorating plasma Se depletion and Al retention in ESRD patients on long-term dialysis. In this study, we examined the effects of Zn supplementation on plasma $\mathrm{Al}$ and Se status and oxidative stress in both plasma and peripheral blood mononuclear cells (PBMCs) in Zn-deficient, dialysis patients with higher than normal Al concentrations. 


\section{Experimental Section}

\subsection{Patients}

Between January and December 2007, Zn-deficient patients (plasma Zn concentrations less than $80 \mathrm{mg} / \mathrm{dL}$ ) with higher than normal plasma Al status (more than $30 \mu \mathrm{g} \mathrm{Al} / \mathrm{L}$ ) [21] on regular CAPD or HD from the renal dialysis unit were enrolled. All patients with less than 6 months of follow-up, had a recent episode of peritonitis within one month, or patients who were more than 70 years of age were excluded. CAPD patients used $2.5 \%$ glucose bags for 3 exchanges and a $7.5 \%$ glucose bag for 1 exchange daily. HD patients regularly received a minimum of $12 \mathrm{~h}$ HD treatment per week ( 3 sessions of $4 \mathrm{~h}$ each) with a high-flux membrane dialyzer. In all participants, none had smoking, alcohol consumption, and gastrointestinal disorders, liver diseases, cancers, mental retardation or dementia, psychiatric illness, received immune suppressant drugs and Al hydroxide phosphate binders, and supplementation with natural herbs, antioxidants, vitamins/minerals, and fish oils. All patients were clinically stable condition as outpatients. In clinical characteristics of patients, hypertension, ischemic heart disease, dyslipidemia, diabetes mellitus, and some drugs use were also recorded.

Patients were divided into two groups according to plasma Al concentrations (HA group; $\mathrm{Al}>50 \mu \mathrm{g} / \mathrm{L}$ and $\mathrm{Al}$ of $>30 \mu \mathrm{g} / \mathrm{L}$ to $\leq 50 \mu \mathrm{g} / \mathrm{L}$ were classified as MA group). The cut-off levels for $\mathrm{Al}$ were selected on the basis of our previous study and the median laboratory value of Al was $50 \mu \mathrm{g} / \mathrm{L}$ [21]. All participants received oral supplementation with $11 \mathrm{mg}$ elemental $\mathrm{Zn}$ per day (78-mg Zn gluconate) for two months. Zn was administered after dinner and the daily dose was based on the recommendations as described by Wang et al. [26]. In addition, healthy subjects (control) of similar age and gender who did not receive $\mathrm{Zn}$ supplementation were included. All subjects signed an informed consent statement prior to inclusion in the study. The study protocol was approved by the ethics in human research committee of Kuang Tien General Hospital.

\subsection{Biochemical Analyses}

Peripheral blood samples were drawn in the morning from participants between 07:30 and 09:00, after an overnight fast of $12 \mathrm{~h}$ at baseline, at one month, and again after two months of $\mathrm{Zn}$ treatment. Plasma concentrations of albumin, hemoglobin, blood urea nitrogen (BUN), creatinine, triglyceride, and glucose were determined using a Hitachi 7050 automatic analyzer (Hitachi Corp., Tokyo, Japan). Urea clearance calculated as $\mathrm{Kt} / \mathrm{V}$, where $\mathrm{K}$ is a constant, $\mathrm{t}$ is time, and $\mathrm{V}$ is total body water. The estimated glomerular filtration rate (GFR) was obtained using the Modification of Diet in Renal Disease (MDRD) study equation [27].

\subsection{Determination of $\mathrm{Al}, \mathrm{Zn}$, and $\mathrm{Se}$}

Plasma Al concentration was determined by atomic absorption spectrophotometer (932AA, GBC, Australia) with a graphite furnace. The instrument was adjusted to a wavelength of $309.3 \mathrm{~nm}$, with a slit of $0.5 \mathrm{~nm}$, and used a hollow cathode Al lamp. The lamp current was $8.0 \mathrm{~mA}$, the integration time was $1 \mathrm{~s}$, and double-beam and D2-background correction were used. The concentrations of plasma $\mathrm{Zn}$ were also measured by flame atomic absorption spectrophotometer (932 plus, GBC, Australia) using an 
air-acetylene flame without background correction at $213.9 \mathrm{~nm}$ [28]. Triplicate absorbance readings were taken for each sample in the peak-height mode. Samples were digested in a $\mathrm{H}_{2} \mathrm{O}_{2} / \mathrm{HNO}_{3}$ mixture in a start D microwave-assisted digestion system (Milestone Microwave Labstation ETHOSD) and subsequently brought up the volume with double deionized water.

For the determination of plasma Se, atomic absorption spectrophotometry with the accessory hydride generation system (HG 3000, GBC, Australia) was used. Samples were digested for a total of $10.5 \mathrm{~h}$ with initial temperature of $60{ }^{\circ} \mathrm{C}$ for $1-1.5 \mathrm{~h}$, followed by increasing temperatures on $20{ }^{\circ} \mathrm{C}$ increments and finally heated up to $225^{\circ} \mathrm{C}$ for $2 \mathrm{~h}$ in a mixture of $3.2 \mathrm{~mL}$ nitric acid $(16 \mathrm{~N})$, and $0.8 \mathrm{~mL}$ concentrated perchloric acid to convert all Se species to selenate. The reduction of selenate was completed within 30 min at a block temperature of $120^{\circ} \mathrm{C}$ [29]. Accuracy of this method was confirmed by comparing to serum reference materials (level 2, NO0371, Seronorm, Nycomed, Oslo, Norway).

\subsection{Measurement of Plasma Oxidative Stress}

The extent of lipid peroxidation was determined by assaying the formation of malondialdehyde (MDA). Briefly, plasma samples were mixed with 3\% sodium dodecyl sulfate, $0.1 \mathrm{~N} \mathrm{HCl}, 10 \%$ phosphotungstic acid, and thiobarbituric acid, and then incubated at $95^{\circ} \mathrm{C}$ for $60 \mathrm{~min}$. The $n$-butanol was added and the mixture was shaken vigorously. After centrifugation at $12,000 \times g$ and $4{ }^{\circ} \mathrm{C}$ for $15 \mathrm{~min}$, the absorbance of the upper layer was read at $530 \mathrm{~nm}$ with excitation at $485 \mathrm{~nm}$ [4]. The MDA levels were calculated using the 1,1,3,3-tetraethoxypropane as standards.

\subsection{ROS Concentrations in Isolated PBMCs}

PBMCs of all participants were isolated from peripheral blood by FICOLL density gradient centrifugation and re-suspended with RPMI 1640 medium. PBMCs $\left(5 \times 10^{5}\right)$ were incubated with $20 \mathrm{ng} / \mathrm{mL}$ of dichlorodihydrofluorescein diacetate (H2DCF-DA) for one hour. The whole-cell ROS concentrations were quantified, and the results were expressed as ROS concentrations per total protein concentration ( $\mathrm{pm}$ DCF/mg protein). Protein content was determined using the Coomassie protein assay (Pierce, Rockford, IL, USA) with bovine serum albumin as the standard.

\subsection{Measurement of Plasma Antioxidant Enzyme Activities}

The plasma superoxide dismutase (SOD) activity was determined with SOD assay kits (Cayman, Ann Arbor, Michigan, USA); one unit was defined as the amount of enzyme necessary to produce $50 \%$ dismutation of the superoxide radicals. The absorbance was measured at $450 \mathrm{~nm}$. The activity of SOD was expressed in unit per mL. In addition, GPx activity was determined using a commercial kit supplied by Cayman Chemical (cat \#703102). Oxidized glutathione (GSSG) produced from reducing reactive oxygen species was recycled by NADPH and glutathione reductase to reduced glutathione (GSH). Therefore, the rate of NADPH consumption was utilized as a measurement of the rate of GSSG formation. The plasma samples were mixed with the stock solution containing NADPH, GSH and excess glutathione reductase, and incubated at $37^{\circ} \mathrm{C}$ for $5 \mathrm{~min}$, followed by addition of $20 \mu \mathrm{L}$ of cumene hydroperoxide as a substrate. The GPx activities were expressed as nmol NADPH oxidized $/ \mathrm{min} / \mathrm{mL}$. 


\subsection{Statistical Analysis}

Each value was expressed as the mean $\pm \mathrm{SD}$ or medians (inter-quartile range, IQR), depending on the normality of data distribution (Shapiro-Wilk test). Comparisons of different variables were made by chi-square test, student's $t$-test, one-way repeated measures analysis of variance (ANOVA), or Friedman repeated measures ANOVA on ranks, as appropriate. A two-tailed $p$ value $<0.05$ was considered statistically significant. In addition, Pearson's or Spearman's correlation coefficients were performed to identify correlations of blood variables.

\section{Results}

\subsection{Clinical Results}

For clinical characteristics of patients, diabetes mellitus (HA 41\%; MA 40\%), hypertension (HA 20\%; MA 25\%), ischemic heart disease (HA 12\%; MA 15\%), and dyslipidemia (HA 25\%; MA 30\%) were recorded. In addition, the percentages of some drugs used, such as insulin (HA 17\%; MA 20\%), sulfonylurea (HA 25\%; MA 20\%), $\mathrm{Ca}^{2+}$ channel antagonists (HA 26\%; MA 25\%), and beta-blocker (HA 12\%; MA 15\%), were similar between the two groups of patients.

Relative to healthy controls, Zn-deficient patients had high BUN and plasma creatinine concentrations $(p<0.05)$, but had low hemoglobin and albumin concentrations (Table 1). Compared with MA group patients, patients in HA group had lower baseline hemoglobin concentrations. The concentrations of all other variables tested were comparable between the two patient groups. There were no particular subjective symptoms observed for the Zn-treated patients.

Table 1. Baseline characteristics of the study group subjects ${ }^{1,2,3}$.

\begin{tabular}{|c|c|c|c|}
\hline & $\begin{array}{c}\text { HA Group Patients } \\
(n=24)\end{array}$ & $\begin{array}{l}\text { MA Group Patients } \\
\qquad(n=20)\end{array}$ & $\begin{array}{l}\text { Healthy Subjects } \\
\qquad(n=25)\end{array}$ \\
\hline \multicolumn{4}{|c|}{ Basic clinical characteristics } \\
\hline Age (years) & $53 \pm 6$ & $55 \pm 7$ & $53 \pm 7$ \\
\hline Gender (M/F) & $9 / 15$ & $8 / 12$ & $9 / 16$ \\
\hline Dialysis modality (CAPD/HD) & $19 / 5$ & $15 / 5$ & - \\
\hline Dialysis duration (years) & $5 \pm 2$ & $6 \pm 1$ & - \\
\hline Body mass index, BMI $\left(\mathrm{kg} / \mathrm{m}^{2}\right)$ & $22 \pm 3$ & $22 \pm 2$ & $24 \pm 3$ \\
\hline $\mathrm{BUN}(\mathrm{mg} / \mathrm{dL})$ & $52(41-74)^{b}$ & $56(40-78)^{\mathrm{b}}$ & $20(12-26)^{\mathrm{a}}$ \\
\hline Creatinine $(\mathrm{mg} / \mathrm{dL})$ & $11(9-13)^{b}$ & $11(10-12)^{b}$ & $2(2-3)^{a}$ \\
\hline Albumin $(\mathrm{mg} / \mathrm{dL})$ & $3.2 \pm 0.3^{\mathrm{a}}$ & $3.3 \pm 0.4^{\mathrm{a}}$ & $4.8 \pm 0.5^{b}$ \\
\hline Hemoglobin $(\mathrm{gm} \%)$ & $9.2 \pm 1.1^{\mathrm{a}}$ & $10.0 \pm 1.0^{b}$ & $16.1 \pm 2.1^{\mathrm{c}}$ \\
\hline nPNA (g/kg/day) & $0.9 \pm 0.1$ & $1.0 \pm 0.3$ & - \\
\hline $\operatorname{GFR}\left(\mathrm{mL} / \mathrm{min} / 1.73 \mathrm{~m}^{2}\right)$ & $3.6(3.2-4.4)$ & $4.0(3.6-5.3)$ & - \\
\hline $\mathrm{Kt} / \mathrm{V}$ (/week) & $2.0 \pm 0.4$ & $2.1 \pm 0.5$ & - \\
\hline \multicolumn{4}{|c|}{ Essential and non-essential trace metals } \\
\hline $\mathrm{Zn}(\mathrm{mg} / \mathrm{dL})$ & $49.2 \pm 7.7^{\mathrm{a}}$ & $54.2 \pm 9.8^{\mathrm{a}}$ & $98.9 \pm 6.4^{b}$ \\
\hline $\mathrm{Al}(\mu \mathrm{g} / \mathrm{L})$ & $73.3(57.2-86.3)^{\mathrm{c}}$ & $41.7(35.5-46.3)^{\mathrm{b}}$ & $25.9(18.5-27.8)^{\mathrm{a}}$ \\
\hline $\mathrm{Se}(\mathrm{ng} / \mathrm{mL})$ & $46.1 \pm 10.2^{\mathrm{a}}$ & $53.2 \pm 16.9^{\mathrm{a}}$ & $106.4 \pm 12.7^{b}$ \\
\hline
\end{tabular}


Table 1. Cont.

\begin{tabular}{cccc}
\hline & Oxidant-antioxidant status & & \\
MDA (nmol/L) & $6.9(6.4-7.7)^{\mathrm{c}}$ & $6.0(5.4-6.8)^{\mathrm{b}}$ & $2.9(2.5-3.4)^{\mathrm{a}}$ \\
ROS in PBMCs (pm DCF/mg prteoin) & $315.2 \pm 58.1^{\mathrm{c}}$ & $272.5 \pm 77.9^{\mathrm{b}}$ & $105.3 \pm 45.3^{\mathrm{a}}$ \\
GPx (nmol/min/mL) & $48.8 \pm 6.3^{\mathrm{a}}$ & $50.5 \pm 8.4^{\mathrm{a}}$ & $85.2 \pm 6.1^{\mathrm{b}}$ \\
SOD (U/mL) & $3.1(3.0-3.4)^{\mathrm{a}}$ & $3.4(3.0-4.7)^{\mathrm{a}}$ & $8.3(7.4-9.1)^{\mathrm{b}}$ \\
\hline
\end{tabular}

\footnotetext{
${ }^{1}$ Values are mean \pm SD or medians (IQR). ${ }^{2}$ Values in the same row with different superscripts $(a, b, c)$ are significantly different $(p<0.05) .{ }^{3} \mathrm{HA}$ group $=$ baseline plasma $\mathrm{Al}>50 \mu \mathrm{g} / \mathrm{L} ; \mathrm{MA}$ group $=$ baseline plasma $\mathrm{Al}>30$ to $\leq 50 \mu \mathrm{g} / \mathrm{L}$. $\mathrm{BUN}=$ blood urea nitrogen; nPNA = protein equivalent of total nitrogen appearance normalized to body weight; $\mathrm{GFR}=$ glomerular filtration rate; $\mathrm{Kt} / \mathrm{V}=$ clearance of urea normalized to total body water. Se $=$ selenium; $\mathrm{Zn}=\mathrm{zinc}$; $\mathrm{Al}=$ aluminum; $\mathrm{MDA}=$ malondialdehyde; $\mathrm{ROS}=$ reactive oxygen species; $\mathrm{SOD}=$ superoxide dismutase; $\mathrm{GPx}=$ glutathione peroxidase.
}

Figure 1. Plasma concentrations of (A) hemoglobin, (B) albumin, and (C) GFR in HA group patients; (D) hemoglobin, (E) albumin, and (F) GFR in MA group patients. Bars are mean (SD) or median (IQR), depending on the normality of data distribution; bar with different superscripts are significantly different $(p<0.05)$. Values above the box plots are outliers. HA group = baseline plasma $\mathrm{Al}>50 \mu \mathrm{g} / \mathrm{L} ; \mathrm{MA}$ group $=$ baseline plasma $\mathrm{Al}>30$ to $\leq 50 \mu \mathrm{g} / \mathrm{L} .1$ month $=1$ month of treatment; 2 month $=2$ months of treatment (end).
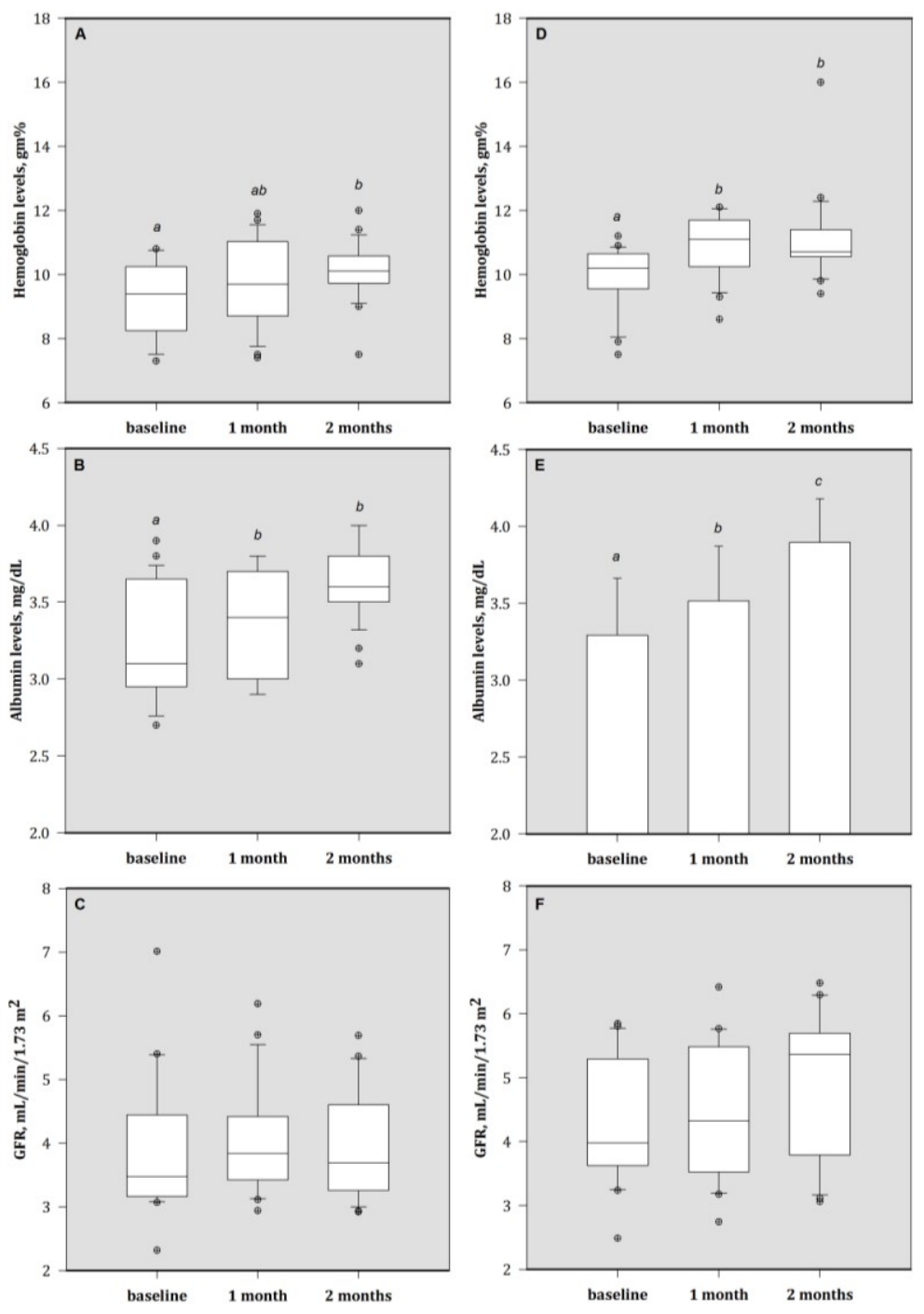
After two months, patients who received $\mathrm{Zn}$ supplementation had higher hemoglobin and albumin concentrations compared to their baseline values (Figure 1). As compared with baseline values, patients in the MA group had non-significantly higher values of GFR after two-month Zn treatment.

\subsection{Plasma Metal Status}

At baseline, patients had low plasma Se concentrations than the healthy subjects (Table 1). At the end of study, these patients in MA group had higher Se concentrations compared to their baseline values (Figure 2). Patients in both MA and HA groups showed significantly increases in plasma $\mathrm{Zn}$ concentrations after the two-month treatment. The elevation in plasma $\mathrm{Zn}$ concentrations that was faster for MA group comparative to the HA group. At the end of $\mathrm{Zn}$ treatment, patients had decreased plasma $\mathrm{Al}$ concentrations compared to their baseline values.

Figure 2. Plasma concentrations of (A) Se, (B) Zn, and (C) Al in HA group patients; (D) Se, (E) Zn, and (F) Al in MA group patients. Bars are mean (SD) or median (IQR), depending on the normality of data distribution; bar with different superscripts are significantly different $(p<0.05)$. Values above the box plots are outliers. HA group = baseline plasma $\mathrm{Al}>50 \mu \mathrm{g} / \mathrm{L} ; \mathrm{MA}$ group = baseline plasma $\mathrm{Al}>30$ to $\leq 50 \mu \mathrm{g} / \mathrm{L}$. Se = selenium; $\mathrm{Zn}=$ zinc; and $\mathrm{Al}=$ aluminum. 1 month $=1$ month of treatment; 2 month $=2$ months of treatment (end).
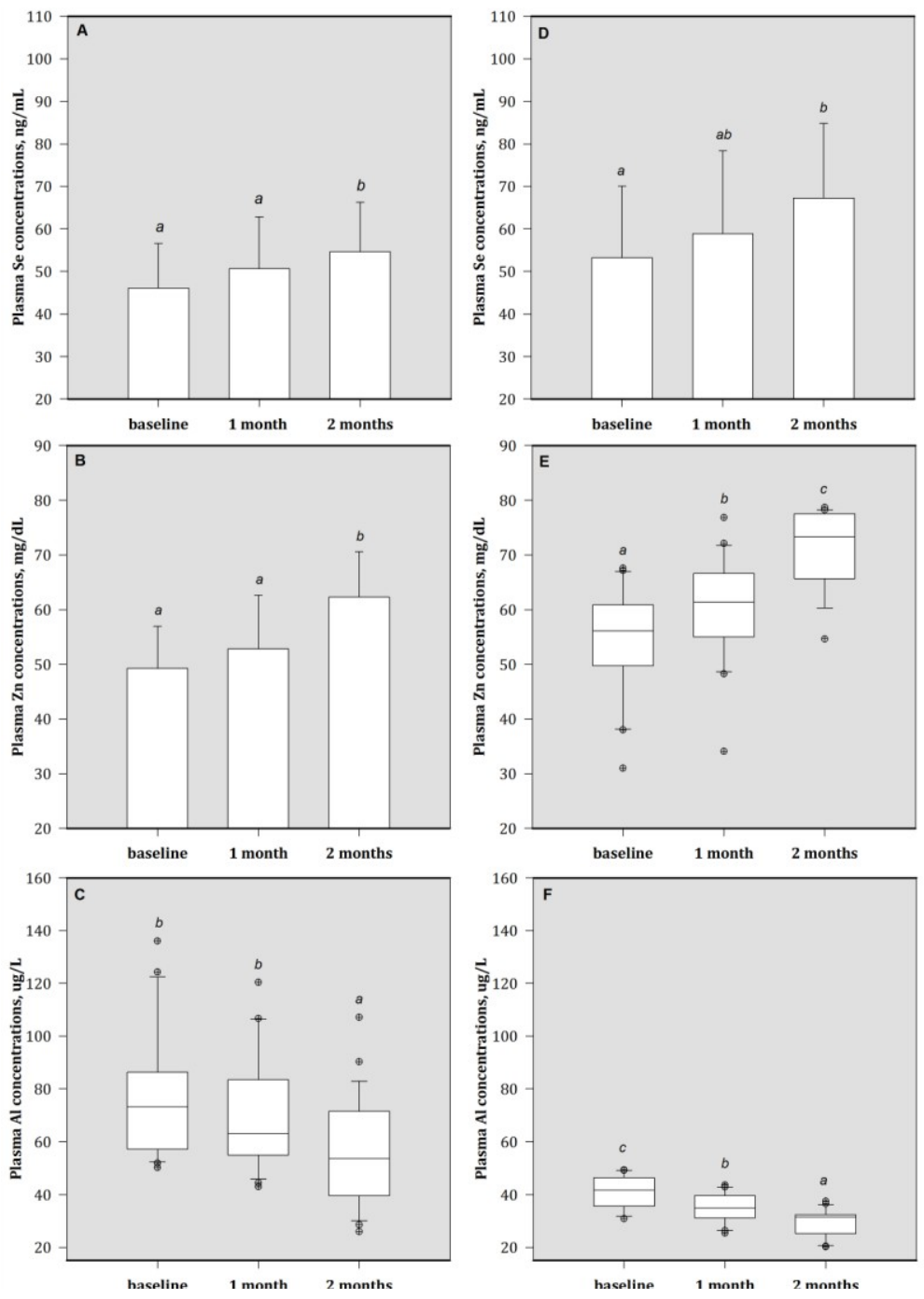


\subsection{Oxidative Stress Status}

Baseline concentrations of the plasma oxidative product MDA were higher in patients compared to healthy subjects (Table 1). Further, plasma MDA concentrations were highest in the HA group patients.

For Zn-supplemented patients, decreases in plasma MDA concentrations were observed after one month. At the end of $\mathrm{Zn}$ treatment, these patients had significantly decreased MDA concentrations compared to their baseline values (Figure 3). Additionally, similar trends were found for the ROS concentrations in PBMCs of both patient groups. Compared to HA group, patients in MA group had lower ROS concentrations, at the end of the study (data not shown).

Figure 3. The concentrations of (A) plasma MDA and (B) peripheral blood mononuclear cells (PBMCs)' ROS in HA group patients; (C) plasma MDA and (D) ROS concentrations in MA group patients. Bars are mean (SD) or median (IQR), depending on the normality of data distribution; bar with different superscripts are significantly different $(p<0.05)$. Values above the box plots are outliers. HA group = baseline plasma $\mathrm{Al}>50 \mu \mathrm{g} / \mathrm{L}$; MA group = baseline plasma $\mathrm{Al}>30$ to $\leq 50 \mu \mathrm{g} / \mathrm{L}$. MDA $=$ malondialdehyde; $\mathrm{ROS}=$ reactive oxygen species. 1 month $=1$ month of treatment; 2 month $=2$ months of treatment (end).
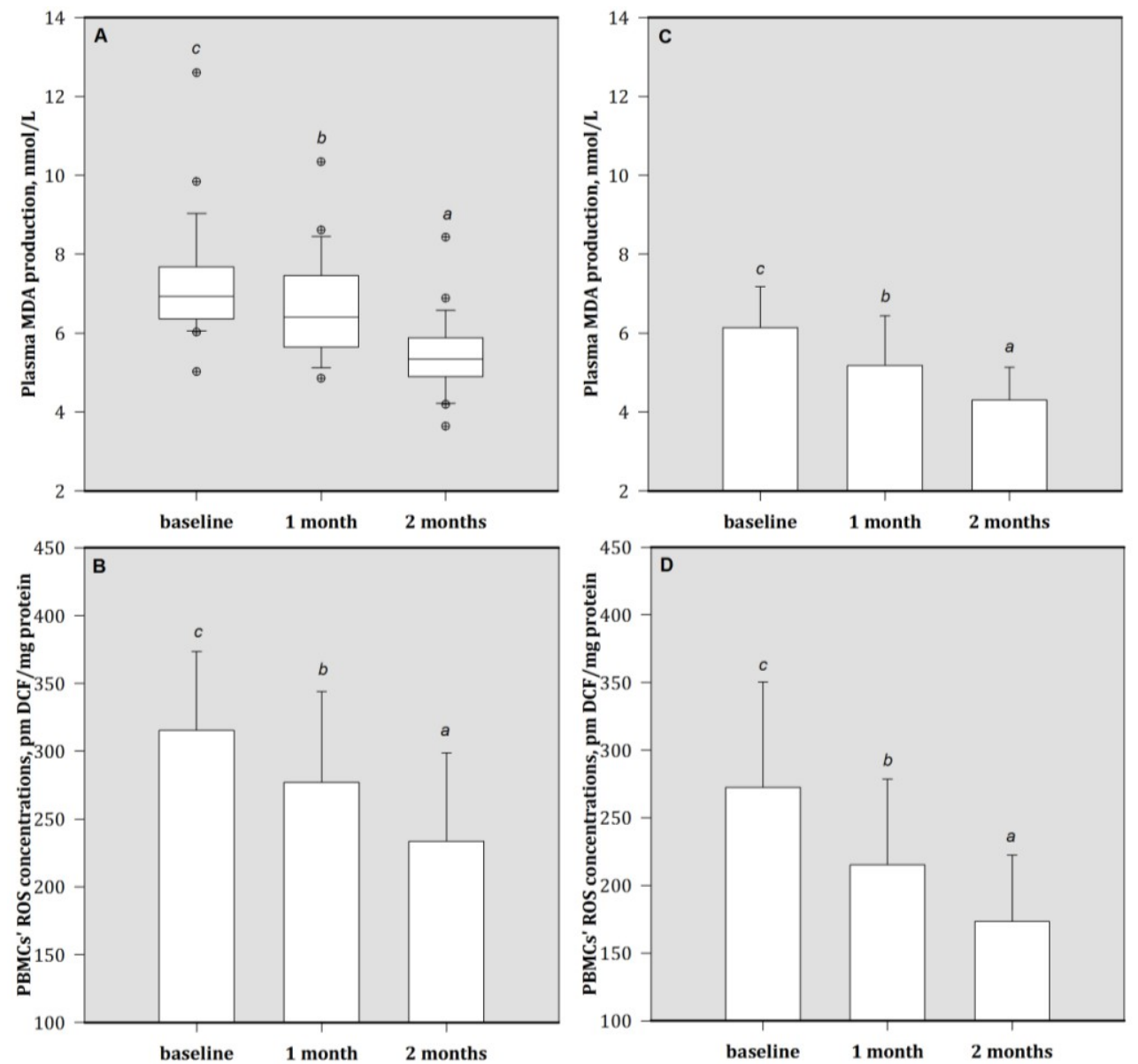

At baseline, there were significant reductions in antioxidant enzyme GPx and SOD activities in these patients. Zn supplementation for the HA group patients did not change the activity of SOD after one month. After two months, these patients in both MA and HA groups showed increased both GPx and SOD activities at the end of study (Figure 4). 
Figure 4. The plasma activities of (A) GPx and (B) SOD in HA group; the plasma (C) GPx and (D) SOD activities in MA group. Bars are median (IQR), and with different superscripts are significantly different $(p<0.05)$. Values above the box plots are outliers. HA group = baseline plasma $\mathrm{Al}>50 \mu \mathrm{g} / \mathrm{L} ; \mathrm{MA}$ group = baseline plasma $\mathrm{Al}>30$ to $\leq 50 \mu \mathrm{g} / \mathrm{L}$. $\mathrm{GPx}=$ glutathione peroxidase; $\mathrm{SOD}=$ superoxide dismutase. 1 month $=1$ month of treatment; 2 month $=2$ months of treatment (end).
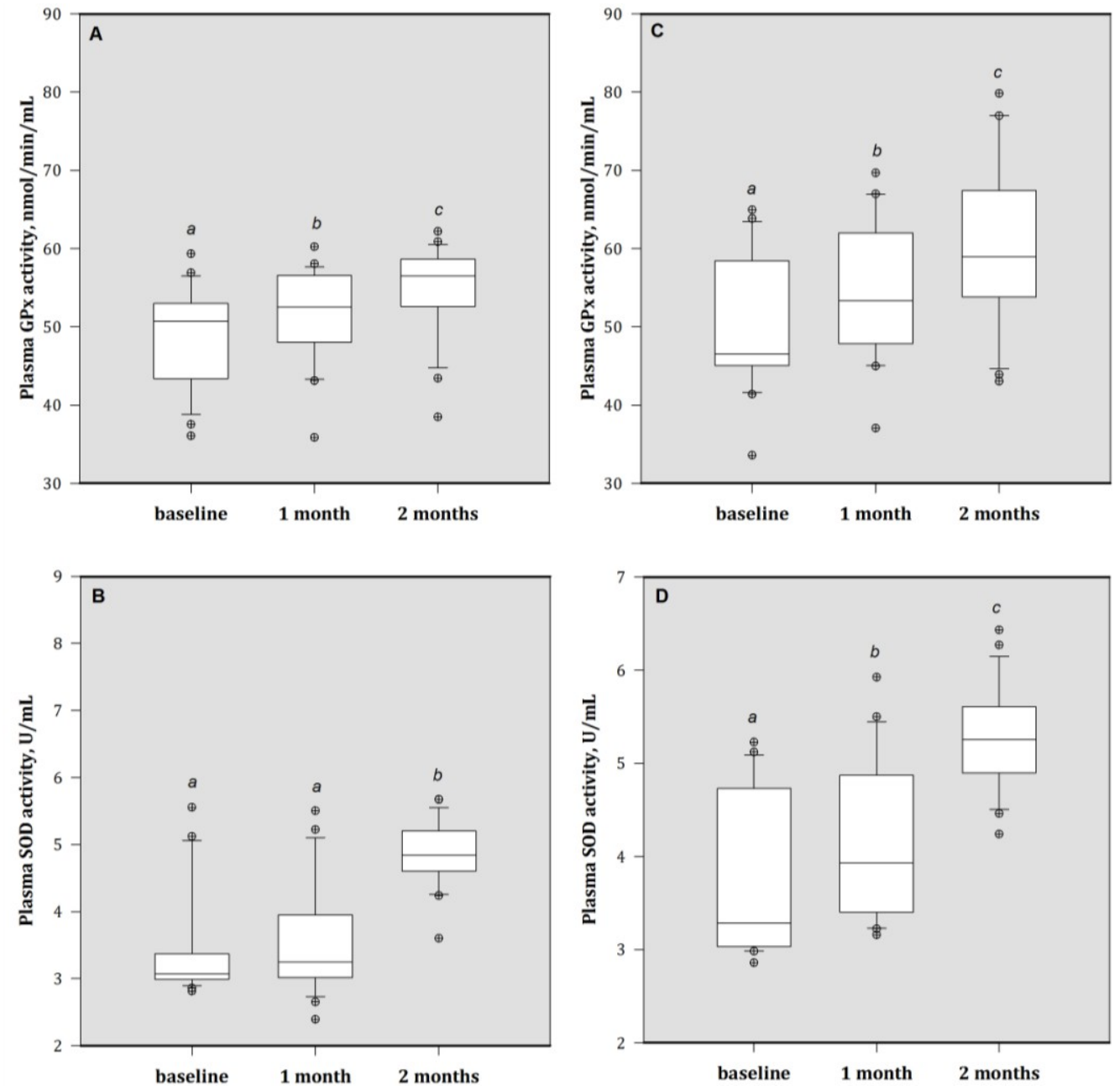

\subsection{Correlations between Al, Other Metals, and Oxidative Stress}

After two months of $\mathrm{Zn}$ administration, plasma $\mathrm{Zn}$ concentrations were correlated with $\mathrm{Al}$, Se, MDA concentrations, and SOD activities in both HA and MA groups (Table 2). Further, partial correlation analysis indicated that the correlation between the plasma $\mathrm{Zn}$ and plasma Se was non-significant when the effect of Al was eliminated. 
Table 2. Correlations between plasma $\mathrm{Zn}$ with Al, Se, MDA concentrations, and SOD activities in patients after two months of $\mathrm{Zn}$ supplementation ${ }^{1,2,3,4}$.

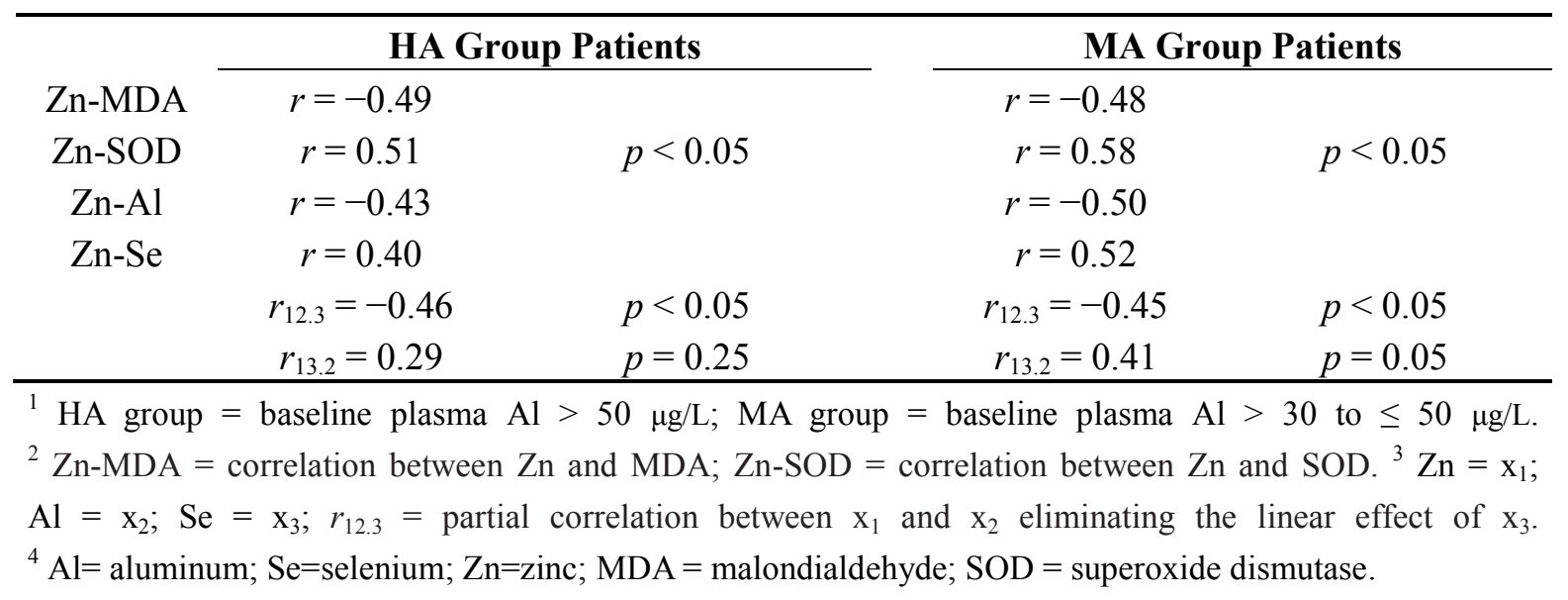

\section{Discussion}

Recent studies have shown that $\mathrm{Zn}$ supplementation increases serum $\mathrm{Zn}$ concentrations, improves taste acuity and the protein catabolic rate [14,30], and raises cholesterol, low-density lipoprotein and high-density lipoprotein concentrations [31-33] in patients with chronic dialysis. Moreover, plasma concentrations of MDA and pro-inflammatory cytokines have been reported to be lower in dialysis patients treated with $\mathrm{Zn}$ supplements [7,34].

In this preliminary investigation, Zn-deficient dialysis patients with higher plasma Al concentrations had low plasma Se concentrations along with decreased activities of antioxidant enzyme GPx than the healthy controls. Several studies have shown that circulating Se concentrations in patients undergoing hemodialysis and CAPD were lower than those in healthy controls [16,17,35], although conflicting results have been reported [36]. Low Se status may be attributed to reduced Se intake, malnutrition, impaired absorption due to high levels of pro-inflammatory cytokine, diminished Se retention due to chronic oxidative stress, or increased loss of Se in the dialysis effluent [2,37]. Further, GPx is a Se dependent protein and circulating GPx activities are responsive to Se status in the biological systems [38]. Kidneys can accumulate the highest amounts of Se and are the major source of plasma GPx [39]; thus, the levels of both Se and GPx can be reduced in ESRD patients.

A negative interaction between plasma $\mathrm{Al}$ and Se in hemodialysis patients has been found [21]. In the present study, plasma Al status appears to have a potential effect on the correlation between $\mathrm{Zn}$ and Se. Thus, increased $\mathrm{Al}$ appeared to suppress Se, which may have been another contributing factor to lower plasma Se status in these dialysis patients. Although Al intoxication can be avoided by water purification, these patients undergoing long-term dialysis still have significant increases in circulating $\mathrm{Al}$ concentrations $[20,21,40]$. In a rat model, $\mathrm{Al}$ administration also disrupted the distribution of Se and decreased GPx activity, which increased oxidative damage in target tissues [23]. Al exposure increases oxidative stress and pro-inflammatory cytokine concentrations that are ameliorated by Se treatment [24], whereas Se does not have a protective effect against the toxic effects of Al [41].

Roles for $\mathrm{Al}$ have been proposed in dialysis encephalopathy, microcytic anemia, arterial stiffness, and osteomalacia in ESRD patients. Possible sources of Al overload for dialysis patients include Al hydroxide phosphate binders, diets that are high in either cooked or processed foods, contamination of 
dialysis machines, and reduced urinary excretion of $\mathrm{Al}$ in long-term dialysis patients $[21,42]$. Furthermore, another major contributor to accumulation of $\mathrm{Al}$ was uremic compounds in patients undergoing chronic dialysis [43]. Kinetic analysis from peritoneal patients has shown that the half-life of Al elimination is probably approximately seven years [44]. The chelating agent deferoxamine can be used to remove excess Al, whereas some deleterious effects were noted [45]. Apparently, effective Al reduction in the circulation is likely to be an important therapeutic target.

Compared to healthy subjects, patients also showed increased plasma production of MDA, higher intracellular ROS concentrations in PBMCs, and lower antioxidant enzyme SOD activities. Some studies indicated that chronic dialysis patients had significantly higher oxidative stress $[3,4,46]$. Zn plays a critical structural role for SOD and can stabilize biological membranes to decrease their susceptibility to oxidative stress. A pronounced decrease in plasma $\mathrm{Zn}$ concentrations among patients with increased Al concentrations was noted in patients with chronic renal insufficiency [47]. Al hydroxide phosphate binders used by patients can interfere with $\mathrm{Zn}$ status [48]. In a rat model, the interaction between $\mathrm{Al}$ and Zn interfered with SOD activities [49]. Thus, higher plasma Al concentrations may interfere with both $\mathrm{Zn}$ and Se homeostasis, which consequently leads to low plasma $\mathrm{Zn}$ and Se concentrations and high oxidative stress in long-term dialysis patients.

In our present preliminary results, $\mathrm{Zn}$ administration decreased plasma $\mathrm{Al}$ concentrations, which was linked to lower MDA concentrations and higher SOD activity. Once plasma Zn status had increased, this may have contributed to ameliorating their worsening renal function by reducing Al retention in these patients. Increased Zn status improves the intestinal barrier integrity [50] may decrease Al concentrations in the circulation.

On the other hand, hemoglobin and albumin status are influenced by numerous factors but are widely used as markers of nutritional status, and as strong predictors of mortality and morbidity [3]. Our present results show that patients receiving $\mathrm{Zn}$ had higher plasma concentrations of hemoglobin and albumin. $\mathrm{Zn}$ supplementation may improve the acuity of taste and smell and gastrointestinal function, increase food intake, and reduce protein-energy wasting [2,30,51]. Thus, The $\mathrm{Zn}$-deficient patients who receive $\mathrm{Zn}$ supplementation have improvements in their oxidant-antioxidant balance and nutritional status [13,14], which likely contributes to their increased plasma Se status.

\section{Conclusions}

Long-term dialysis patients with low plasma Zn concentrations had reduced plasma concentrations of Se. Dietary intake data for Se and $\mathrm{Zn}$ was not available, which we consider to be a limitation. The study was also limited in comparing the variables based on dialysis modalities and the potential interaction between $\mathrm{Al}$ and renal function. The present pilot study is not a randomized trial, the results show that $\mathrm{Zn}$ administration increased the initially low plasma $\mathrm{Zn}$ concentrations concomitant with Se concentrations in patients and contributed to reducing their high plasma Al concentrations and oxidative stress. Additional Zn supplement may be necessary to alleviate symptoms of long-term dialysis. Further large-scale studies will be needed to clarify the effects of $\mathrm{Zn}$ supplement on Al metabolism in long-term dialysis patients. 


\section{Acknowledgements}

Research supported in part by a grant from Kuang Tien General Hospital, Taichung, Taiwan.

\section{Conflict of Interest}

The authors declare no conflict of interest.

\section{References}

1. Al Wakeel, J.S.; Mitwalli, A.H.; Al Mohaya, S.; Abu-Aisha, H.; Tarif, N.; Malik, G.H.; Hammad, D. Morbidity and mortality in ESRD patients on dialysis. Saudi J. Kidney Dis. Transpl. 2002, 13, 473-477.

2. Guo, C.H.; Wang, C.L.; Chen, P.C. Micronutrient Metabolism in Hemodialysis Patients. In Hemodialysis-Different Aspects; Maria, G.P., Ed.; InTech: Rijeka, Croatia, 2011; pp. 173-204.

3. Guo, C.H.; Chen, P.C.; Yeh, M.S.; Hsiung, D.Y.; Wang, C.L. Cu/Zn ratios are associated with nutritional status, oxidative stress, inflammation, and immune abnormalities in patients on peritoneal dialysis. Clin. Biochem. 2011, 44, 275-280.

4. Guo, C.H.; Wang, C.L.; Chen, P.C.; Yang, T.C. Linkage of some trace elements, peripheral blood lymphocytes, inflammation, and oxidative stress in patients undergoing either hemodialysis or peritoneal dialysis. Perit. Dial. Int. 2011, 31, 583-591.

5. Zachara, B.A.; Gromadzinska, J.; Palus, J.; Zbrog, Z.; Swiech, R.; Twardowska, E.; Wasowicz, W. The effect of selenium supplementation in the prevention of DNA damage in white blood cells of hemodialyzed patients: A pilot study. Biol. Trace Elem. Res. 2011, 142, 274-283.

6. Fujishima, Y.; Ohsawa, M.; Itai, K.; Kato, K.; Tanno, K.; Turin, T.C.; Onoda, T.; Endo, S.; Okayama, A.; Fujioka, T. Serum selenium levels in hemodialysis patients are significantly lower than those in healthy controls. Blood Purif. 2011, 32, 43-47.

7. Guo, C.H.; Wang, C.L. Effects of zinc supplementation on plasma copper/zinc ratios, oxidative stress, and immunological status in hemodialysis patients. Int. J. Med. Sci. 2013, 10, 79-89.

8. Ari, E.; Kaya, Y.; Demir, H.; Asicioglu, E.; Keskin, S. The correlation of serum trace elements and heavy metals with carotid artery atherosclerosis in maintenance hemodialysis patients. Biol. Trace Elem. Res. 2011, 144, 351-359.

9. Grzegorzewska, A.E.; Mariak, I. Zinc as a marker of nutrition in continuous ambulatory peritoneal dialysis patients. Adv. Perit. Dial. 2001, 17, 223-229.

10. Yang, C.Y.; Wu, M.L.; Chou, Y.Y.; Li, S.Y.; Deng, J.F.; Yang, W.C.; Ng, Y.Y. Essential trace element status and clinical outcomes in long-term dialysis patients: A two-year prospective observational cohort study. Clin. Nutr. 2012, 31, 630-636.

11. Rucker, D.; Thadhani, R.; Tonelli, M. Trace element status in hemodialysis patients. Semin. Dial. 2010, 23, 389-395.

12. Tonelli, M.; Wiebe, N.; Hemmelgarn, B.; Klarenbach, S.; Field, C.; Manns, B.; Thadhani, R.; Gill, J.; Alberta Kidney Disease Network. Trace elements in hemodialysis patients: A systematic review and meta-analysis. BMC Med. 2009, 7, 25, doi:10.1186/1741-7015-7-25. 
13. Mazani, M.; Argani, H.; Rashtchizadeh, N.; Ghorbanihaghjo, A.; Hamdi, A.; Asghari Estiar, M.; Nezami, N. Effects of zinc supplementation on antioxidant status and lipid peroxidation in hemodialysis patients. J. Ren. Nutr. 2012, doi:10.1053/j.jrn.2012.08.012.

14. Jern, N.A.; VanBeber, A.D.; Gorman, M.A.; Weber, C.G.; Liepa, G.U.; Cochran, C.C. The effects of zinc supplementation on serum zinc concentration and protein catabolic rate in hemodialysis patients. J. Ren. Nutr. 2000, 10, 148-153.

15. Mariak, I.; Grzegorzewska, A.E. Serum zinc concentration with reference to other markers of continuous ambulatory peritoneal dialysis patients status. Pol. Merkur. Lek. 2002, 12, 282-287.

16. Fujishima, Y.; Ohsawa, M.; Itai, K.; Kato, K.; Tanno, K.; Turin, T.C.; Onoda, T.; Endo, S.; Okayama, A.; Fujioka, T. Serum selenium levels are inversely associated with death risk among hemodialysis patients. Nephrol. Dial. Transplant. 2011, 26, 3331-3338.

17. Martí del Moral, L.; Agil, A.; Navarro-Alarcón, M.; López-Ga de la Serrana, H.; Palomares-Bayo, M.; Oliveras-López, M.J. Altered serum selenium and uric acid levels and dyslipidemia in hemodialysis patients could be associated with enhanced cardiovascular risk. Biol. Trace Elem. Res. 2011, 144, 496-503.

18. Salehi, M.; Sohrabi, Z.; Ekramzadeh, M.; Fallahzadeh, M.K.; Ayatollahi, M.; Geramizadeh, B.; Hassanzadeh, J.; Sagheb, M.M. Selenium supplementation improves the nutritional status of hemodialysis patients: A randomized, double-blind, placebo-controlled trial. Nephrol. Dial. Transplant. 2012, doi:10.1093/ndt/gfs170.

19. Jihen el, H.; Imed, M.; Fatima, H.; Abdelhamid, K. Protective effects of selenium (Se) and zinc $(\mathrm{Zn})$ on cadmium $(\mathrm{Cd})$ toxicity in the liver of the rat: Effects on the oxidative stress. Ecotoxicol. Environ. Saf. 2009, 72, 1559-1564.

20. Anees, M.; Mumtaz, A.; Frooqi, S.; Ibrahim, M.; Hameed, F. Serum trace elements (Aluminum, Copper, Zinc) in hemodialysis patients. Biomedica 2011, 27, 106-110.

21. Guo, C.H.; Wang, C.L. Plasma aluminum is a risk factor for oxidative stress and inflammation status in hemodialysis patients. Clin. Biochem. 2011, 44, 1309-1314.

22. Guo, C.H.; Huang, C.J.; Chiou, Y.L.; Hsu, G.S. Alteration of trace element distribution and testis ACE activity in mice with high peritoneal aluminum. Biol. Trace Elem. Res. 2002, 86, 145-157.

23. Guo, C.H.; Hsu, G.S.; Chuang, C.J.; Chen, P.C. Aluminum accumulation induced testicular oxidative stress and altered selenium metabolism in mice. Environ. Toxicol. Pharmacol. 2009, 27, 176-181.

24. Viezeliene, D.; Beekhof, P.; Gremmer, E.; Rodovicius, H.; Sadauskiene, I.; Jansen, E.; Ivanov, L. Selective induction of IL- 6 by aluminum-induced oxidative stress can be prevented by selenium. J. Trace Elem. Med. Biol. 2012, doi:10.1016/j.jtemb.2012.11.001.

25. Rawy, S.M.; Seif Al Nassr, F.M. Zinc sulphate and vitamin E alleviate reproductive toxicity caused by aluminium sulphate in male albino rats. Toxicol. Ind. Health. 2013, doi:10.1177/ 0748233712469650.

26. Wang, A.Y.; Sea, M.M.; Ip, R.; Law, M.C.; Chow, K.M.; Lui, S.F.; Li, P.K.; Woo, J. Independent effects of residual renal function and dialysis adequacy on dietary micronutrient intakes in patients receiving continuous ambulatory peritoneal dialysis. Am. J. Clin. Nutr. 2002, 76, 569-576. 
27. Levey, A.S.; Bosch, J.P.; Lewis, J.B.; Greene, T.; Rogers, N.; Roth, D. A more accurate method to estimate glomerular filtration rate from serum creatinine: A new prediction equation. Ann. Intern. Med. 1999, 130, 461-470.

28. Hsu, G.S.W.; Hsu, C.Y. The relationship between high maternal aluminum ingestion and anemia-related hematologic changes in rats. Asia Pac. J. Clin. Nutr. 1994, 3, 9-13.

29. Norheim, G.; Haugen, A. Precise determination of selenium in tissues using auto-mated wet digestion and an automated hydride generator-atomic absorption spectroscopy system. Acta Pharmacol. Toxicol. 1986, 59 (Suppl. VII), 610-612.

30. Eggert, J.V.; Siegler, R.L.; Edomkesmalee, E. Zinc supplementation in chronic renal failure. Int. J. Pediatr. Nephrol. 1982, 3, 21-24.

31. Chevalier, C.A.; Liepa, G.; Murphy, M.D.; Suneson, J.; Vanbeber, A.D.; Gorman, M.A.; Cochran, C. The effects of zinc supplementation on serum zinc and cholesterol concentrations in hemodialysis patients. J. Ren. Nutr. 2002, 12, 183-189.

32. Roozbeh, J.; Hedayati, P.; Sagheb, M.M.; Sharifian, M.; Hamidian, J.A.; Shaabani, S.; Jalaeian, H.; Raeisjalali, G.A.; Behzadi, S. Effect of zinc supplementation on triglyceride, cholesterol, LDL, and HDL levels in zinc-deficient hemodialysis patients. Ren. Fail. 2009, 31, 798-801.

33. Foster, M.; Petocz, P.; Samman, S. Effects of zinc on plasma lipoprotein cholesterol concentrations in humans: A meta-analysis of randomised controlled trials. Atherosclerosis 2010, 210, 344-352.

34. Rashidi, A.A.; Salehi, M.; Piroozmand, A.; Sagheb, M.M. Effects of zinc supplementation on serum zinc and C-reactive protein concentrations in hemodialysis patients. J. Ren. Nutr. 2009, 19, 475-478.

35. Apostolidis, N.S.; Panoussopoulos, D.G.; Stamou, K.M.; Kekis, P.B.; Paradellis, T.P.; Karydas, A.G.; Zarkadas, C.; Zirogiannis, P.N.; Manouras, A.J. Selenium metabolism in patients on continuous ambulatory peritoneal dialysis. Perit. Dial. Int. 2002, 22, 400-404.

36. Johnson-Davis, K.L.; Fernelius, C.; Eliason, N.B.; Wilson, A.; Beddhu, S.; Roberts, W.L. Blood enzymes and oxidative stress in chronic kidney disease: A cross sectional study. Ann. Clin. Lab. Sci. 2011, 41, 331-339.

37. Pakfetrat, M.; Malekmakan, L.; Hasheminasab, M. Diminished selenium levels in hemodialysis and continuous ambulatory peritoneal dialysis patients. Biol. Trace Elem. Res. 2010, 137, 335-339.

38. Patrick, L. Selenium biochemistry and cancer: A review of the literature. Altern. Med. Rev. 2004, 9, 239-258.

39. Avissar, N.; Ornt, D.B.; Yagil, Y.; Horowitz, S.; Watkins, R.H.; Kerl, E.A.; Takahashi, K.; Palmer, I.S.; Cohen, H.J. Human kidney proximal tubules are the main source of plasma glutathione peroxidase. Am. J. Physiol. 1994, 266, C367-C375.

40. Christie, M.; Lavergne, V.; Sikaneta, T.; Hue, C.S.; Taskapan, H.; Tam, P.W.; Ayoub, P.; Ting, R.; Leblanc, D.; Ghannoum, M. Hyperaluminemia during long-term dialysis: Still relevant today. Am. J. Kidney Dis. 2011, 58, 861-863.

41. Viezeliene, D.; Jansen, E.; Rodovicius, H.; Kasauskas, A.; Ivanov, L. Protective effect of selenium on aluminium-induced oxidative stress in mouse liver in vivo. Environ. Toxicol. Pharmacol. 2011, $31,302-306$. 
42. Centers for Disease Control and Prevention (CDC). Elevated serum aluminum levels in hemodialysis patients associated with use of electric pumps-Wyoming, 2007. MMWR Morb. Mortal. Wkly. Rep. 2008, 57, 689-691.

43. El-khawaga, O.Y.; El-sayed, I.L. Evaluation of trace elements and antioxidants in pre and post hemodialysis of chronic renal failure patients. Int. J. Sci. Nat. 2012, 3, 617-620.

44. Yue, C.S.; Christie, M.; Lavergne, V.; Sikaneta, T.; Taskapan, H.; Mardini, K.; Tam, P.; Ting, R.; Ghannoum, M. Aluminum toxicokinetics in peritoneal dialysis patients. Clin. Toxicol. 2011, 49, 659-663.

45. Crisponi, G.; Dean, A.; Di Marco, V.; Lachowicz, J.I.; Nurchi, V.M.; Remelli, M.; Tapparo, A. Different approaches to the study of chelating agents for iron and aluminium overload pathologies. Anal. Bioanal. Chem. 2013, 405, 585-601.

46. Morishita, Y.; Watanabe, M.; Hirahara, I.; Akimoto, T.; Muto, S.; Kusano, E. Level of 8-OHdG in drained dialysate appears to be a marker of peritoneal damage in peritoneal dialysis. Int. J. Nephrol. Renovasc. Dis. 2012, 5, 9-14.

47. Zumkley, H.; Bertram, H.P.; Lison, A.; Knoll, O.; Losse, H. Aluminum, zinc and copper concentrations in plasma in chronic renal insufficiency. Clin. Nephrol. 1979, 12, 18-21.

48. Dashti-Khavidaki, S.; Khalili, H.; Vahedi, S.M.; Lessan-Pezeshki, M. Serum zinc concentrations in patients on maintenance hemodialysis and its relationship with anemia, parathyroid hormone concentrations and pruritus severity. Saudi J. Kidney Dis. Transpl. 2010, 21, 641-645.

49. Khanna, P.; Nehru, B. Antioxidant enzymatic system in neuronal and glial cells enriched fractions of rat brain after aluminum exposure. Cell. Mol. Neurobiol. 2007, 27, 959-969.

50. Zhong, W.; McClain, C.J.; Cave, M.; Kang, Y.J.; Zhou, Z. The role of zinc deficiency in alcohol-induced intestinal barrier dysfunction. Am. J. Physiol. Gastrointest. Liver Physiol. 2010, 298, G625-G633.

51. Prasad, A.S. The role of zinc in gastrointestinal and liver disease. Clin. Gastroenterol. 1983, 12, 713-741.

(C) 2013 by the authors; licensee MDPI, Basel, Switzerland. This article is an open access article distributed under the terms and conditions of the Creative Commons Attribution license (http://creativecommons.org/licenses/by/3.0/). 